\title{
Anomaly detection on cup anemometers
}

\author{
Enrique Vega, Santiago Pindado, Alejandro Martínez, Encarnación Meseguèr and Luis García
}

\begin{abstract}
The perlomances of two rotor-damaged commercial anemometers (Vector Instruments $\Delta 100$

I.K) were studied. The calibration resuts (i.c. the transler lunction) were very linear, the acrodynamic behavior beine more efficient than the one shown by both anemometers cquiped with undamaged rotors. No detection of the anomaly (the rotors" damage) was possible based on the calibration results. However, the Fourier analysis clearly revealed this anomaly.
\end{abstract}

\section{Introduction}

Anemometer degradation is a well-known problem in the wind encrey industry. $A s$ a cup anemometer loses performance, due to the nomal wear and tear process or due to suelden incidents such as lightning, the wind speed measurement given by the instrument divereses from the reat wind speed. As a conseguence. this clfect can be translated into a wrone wind turbine operation or inaccurate data when studying the energy production of a specilic geographic location, causing a negative impact on the revenue. As aforementioned. this is not a new problem either lor the wind energy sector or in meteorology. Furthennore, it can be said that around $30 \%$ of mast-mounted anemometers retum for recalibration far from normal operational conditions I11.

Cumently, the only solution for keeping ancmoncters in proper working condition is to check them through frequent catibrations [2]. However, the process of taking the anemomcer to the calibration lacility can be unaflordable in terms of cost and is lime-consuming. Calibration-on-the-fictel procedures have been studied as a cost-clfective solution lor redacine anemomeler matintenance and the number of recalibrations 13,4I. In addition, to illustrate the considerable interest of the industry in this matter. several patents and inventions have been developed in an attempl to solve this problem 15-131.
Besides the maintenance problem (recalibration, change of parts, etc), it can be even more important to know as precisely as possible. when a cup anemometer which is working on the field, rejuires some maintenance. 'lhis can be considered an example of the anomaly detection problem. In the industry, anomaly detection is tusually addressed through three different approaches: case-based reasoning, model-based diagnosis and non-parametric models [14]. Regarding loss of performance in cup anemometers. the results of the PHM 201 I Data Challenge Competition are particularly interesting. In the competition, the working condition of several cup anemometers had to be analyzed, comparing the data from paired units installed along a vertical mast [15-17].

In the current work, an anomaly detection process developed at the IIDR/LJPM Instifute II8I is applice, for the first time to two commercial eup anemometers (Vector Instruments AlOO L.K) with damaged rotors after a gute a long period of service. The perfomance of these Class-l anemometers is analyzed and compared to the performance of the same type of anemometers, but equipped with undamaged rotors. The main advantage of the developed methodology is in its simplicity. as the working condition of the cup anemometer is only based on the data from its output signal, with no comparison with a second anemometer dataset required. 

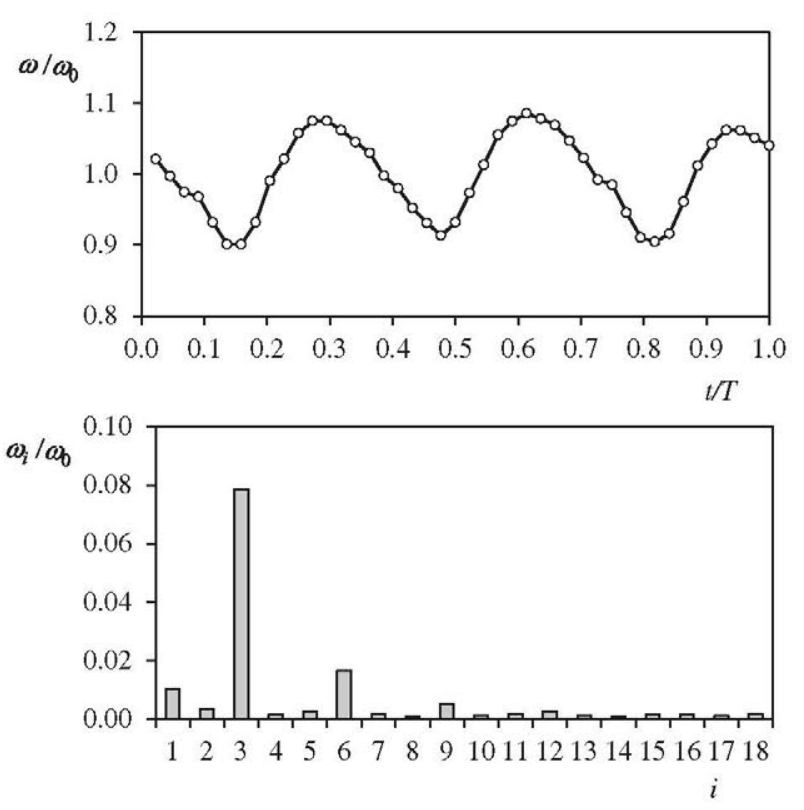

Figure 1. Relative-to-the-average rotational speed, $\omega / \omega_{0}$, of a Thies anemometer during one turn at $8 \mathrm{~m} \mathrm{~s}^{-1}$ wind speed [29] (top) and non-dimensional values of the Fourier series expansion performed at that rotational speed, $\omega_{i} / \omega_{0}$ (bottom).

The results included in this work are part of a full research program carried out since 2011 at the IDR/UPM Institute regarding the cup anemometer performance, which covers a large series of calibration analyses [19], rotor aerodynamics [20-22], the effect of climatic conditions [23] or the ageing problem [24].

The current work is organized as follows. In section 2 the calibration and post-processing process are described. The results are discussed in section 3 and the conclusions are summarized in section 4.

\section{Testing configuration and cases studied}

The cup anemometer performance is commonly evaluated through the transfer function:

$$
V=\mathrm{A} \cdot f+\mathrm{B},
$$

that gives the wind speed, $V$, as a function of the output frequency of the anemometer, $f$. The slope and offset (A and B, respectively) of the above equation have to be defined by a proper calibration process. The transfer function can also be defined in terms of rotational frequency, $f_{r}$, instead of output frequency, $f$ :

$$
V=\mathrm{A}_{r} \cdot f_{r}+\mathrm{B} \text {. }
$$

This new slope, $\mathrm{A}_{r}$, being the result of multiplying calibration constant $\mathrm{A}$ by the number of pulses per turn, $N_{p}$, given by the anemometer [19]. The calibration process performed on the anemometers studied follows MEASNET [25, 26] recommendations (over 13 points and from 4 to $16 \mathrm{~m} \mathrm{~s}^{-1}$ wind speed). At each point (wind speed) of every calibration performed, the anemometer's output was sampled during $20 \mathrm{~s}$
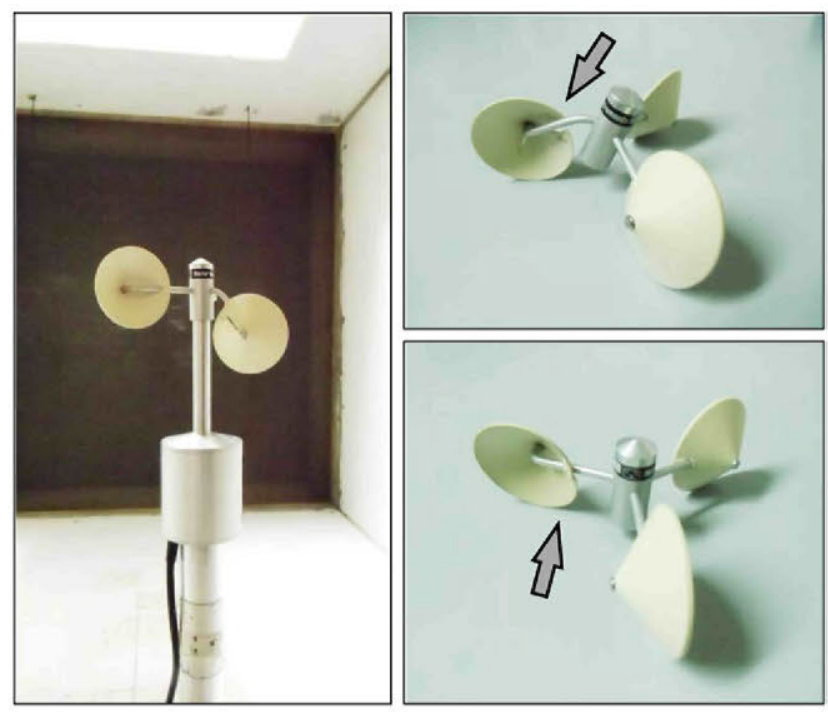

Figure 2. Anemometer 1 at the IDR/UPM calibration wind tunnel (left). Damaged rotor of Anemometer 1 (top right) and Anemometer 2 (bottom right).

at $10000 \mathrm{~Hz}$. The first nine harmonic terms of the rotational speed Fourier expansion:

$$
\begin{aligned}
& \omega(t)=\omega_{0}+\omega_{1} \sin \left(\omega_{0} t+\varphi_{1}\right)+\omega_{2} \sin \left(2 \omega_{0} t+\varphi_{2}\right) \\
& +\omega_{3} \sin \left(3 \omega_{0} t+\varphi_{3}\right) \ldots=\omega_{0}+\sum_{n=1}^{\infty} \omega_{n} \sin \left(n \omega_{0} t+\varphi_{n}\right)
\end{aligned}
$$

were calculated in each sampling of the output signal. In order to characterize the anemometer harmonic performance, averaged values of the non-dimensional harmonic terms, $\bar{\omega}_{i}$, were calculated with data from the 13 points of each calibration procedure:

$$
\bar{\omega}_{i}=\left.\frac{1}{13} \sum_{j=1}^{13} \frac{\omega_{i}}{\omega_{0}}\right|_{j} .
$$

See in figure 1 an example of the Fourier expansion (i.e. the terms in relation to the averaged rotation speed) derived from a commercial cup anemometer output signal. More information about this harmonic characterization of a cup anemometer can be found at [20].

Anemometer calibrations of the study cases were performed in the S4 wind tunnel at the IDR/UPM Institute. This is an open-circuit wind tunnel with a closed test section measuring 0.9 by $0.9 \mathrm{~m}$. It is served by four $7.5 \mathrm{~kW}$ fans with a flow uniformity better than $0.2 \%$ in the testing area. The wind speed in the testing chamber is measured by an Airflow 0.48 Pitot tube connected to a Druck LPM 9481 high-precision pressure transducer, with the electrical signal from the pressure transducer measured by a Keithley 2000 digital multimeter. Temperature and humidity sensors (Vaisala PTU 200 and Vaisala HMP45D) are used to determine the air density value. The rotation frequency of the anemometer is measured with an Agilent 53131A universal counter. Another digital multimeter is used to measure the voltage or current output from the anemometer when required. The uncertainty levels of the calibrations performed at the S4 calibration wind tunnel are 

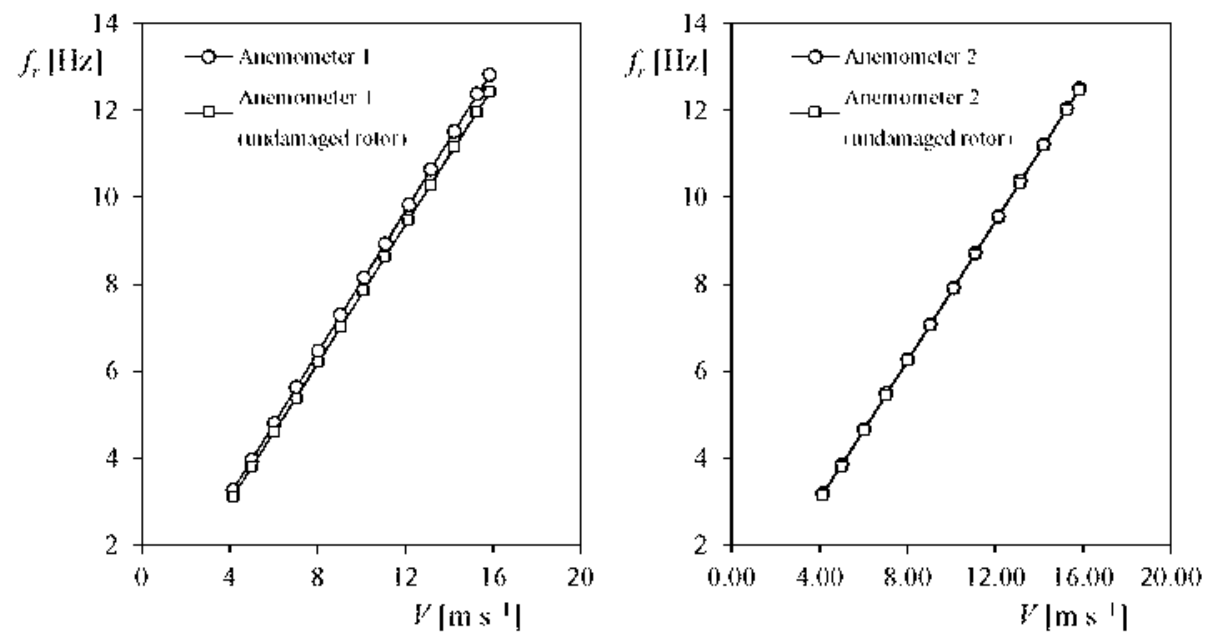

Figure 3. Rotation frequency. $f$. of Anemoneter 1 and Anemomeler 2 plotted as a function of the wind speed. $V$. The results regarding both anemometers equipled with undamaged rotors have been incleded in the graphs.

specified following the ISO/IISC. 17025 standard [27], these levels being $0.1 \mathrm{~m} \mathrm{~s}^{-1}$ for wind speeds from 4 to $10 \mathrm{~m} \mathrm{~s}^{-1}$ and $0.01 V \mathrm{~ms}^{-1}$ for wind speeds. $V$, from 10 to $23 \mathrm{~ms}^{-1}$. More information regarding the anemometer calibration processes at the IDR/L JPM Institute can be found at [19, 22, 28 I.

As indicated in the previous section, two Vector Instruments AIOO I.K cup anemometers were studied, both being damaged after being in service on the field. See in figure 2 pictures of the state of the rotors. The rotor of the first anemometer. herein after denoted as Anemometer I, is heavily damaged, with one cup completely out of pesition. whereas the second one, hereinafter denoted as Anemometer 2 , is Iess damaged.

\section{Results}

In figure 3, the rotation frequency, $f_{r}$, comesponding to the calibrations perlomed on both anemometers, Anemometer 1 and Anemometer 2, is plotted as a function of the wind specel, $V$. In addition. the results comesponding to additionat calibrations perlonned on both anemoneters now equipped with undamaged rotors are included in the graphs. As can be observed in fieure 3, the results of the calibrations were successfully lincar (wilh cometation coclficients above 0.99909 , according to MF $\triangle S N E: T$ procedures $[25,26]$ ).

Besides, the pereentage difference between the rotationat frecuency, $f$, of each anemoncter equipped with its damaged rotor and equipped with the undiamaged rotor, $\left.f_{r}\right|_{n d r}$. calculated in relation to the first one:

$$
\Delta f_{r}=\frac{f_{r}-\left.f_{r}\right|_{\mathrm{ndr}}}{f_{r}},
$$

is ploted as a function of the wind speed, $v$, in figure 4 .

Ihe results are quite surprising, as the damage effect on the rotor seems to increase (in both anemometers) the rotation rate, i.s. the acrodynamice efficiency of the rotor (see figure 4). The possible explanation for these results lies in the new position of the damaged exps within the rotors. In Anemometer I, the damaged cup is out of the wake prodtecd by the other

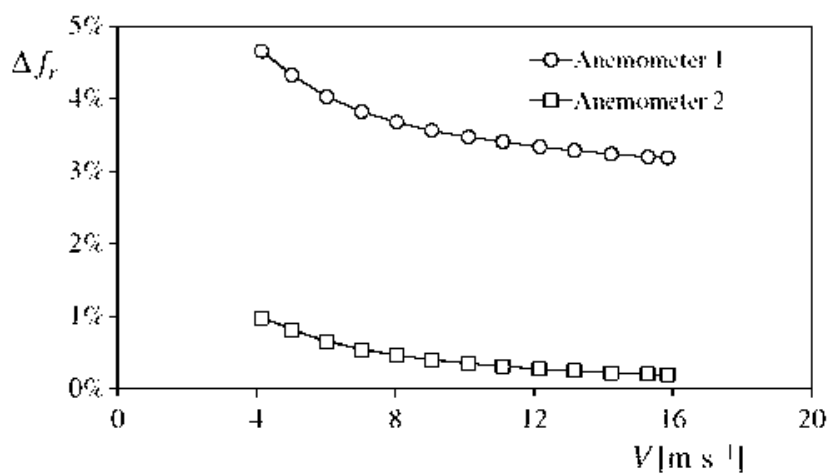

Figure 4. Percentage difference. $A f$. between the rotational frequency. $f$, of each anemomeler equipped with its damaged $\mathrm{mos}$ and equipped with the undanaged rotor. $\left.f_{r}\right|_{\text {rell }}$. catculated in relation to the first one.

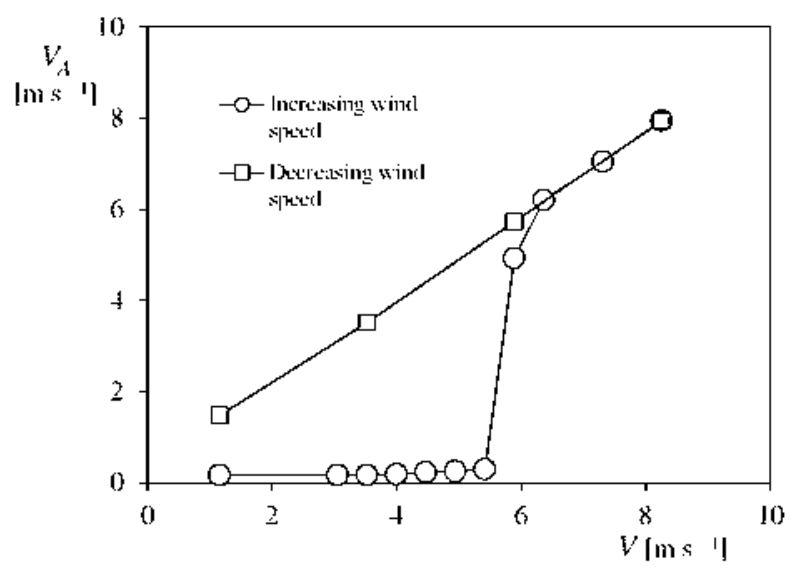

Figure 5. Wind speed measured by nimemometer 1. $v_{A}$. as a function of the wind specel, $V$, in two different situations: increasing wind speeds from $V=1.158$ or $V=7.949 \mathrm{~m} \mathrm{~s}^{-1}$ and decreasing wind specds stating from $V=7.949$ lo $V=1.158 \mathrm{~m} \mathrm{~s}^{-1}$.

cups. whereas one of these is less affected by any wake, as the damaged cup is not aligned with the rotor plane anymore. $\Delta$ s one of the cups is now closer to the rotation axis. the decrease of the rotor's moment of inertia obviously produces higher 

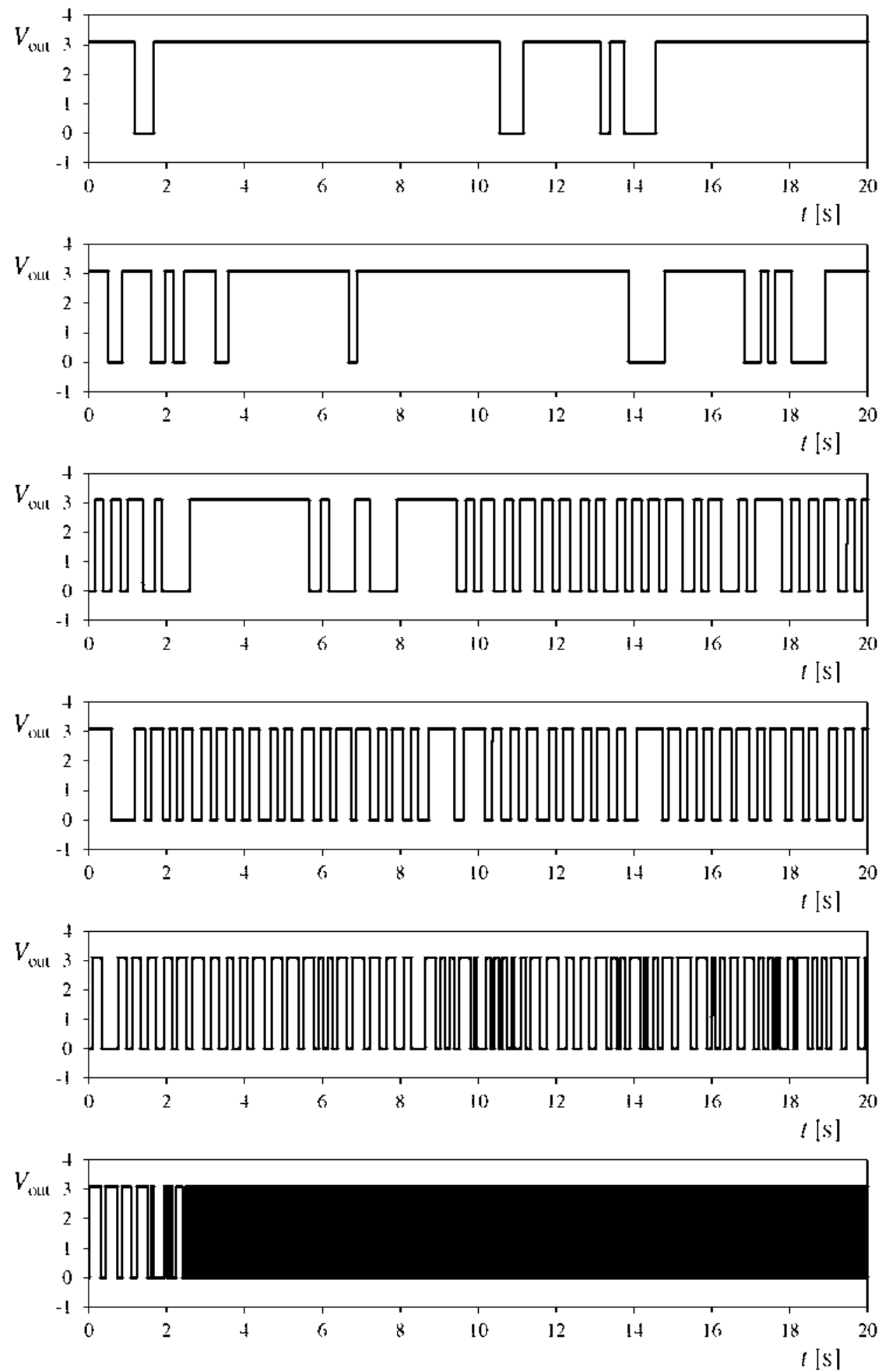

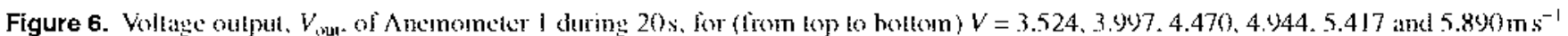
wind spered.

rotation speeds. In order to check this behavior, the calibration perfonmed with the anemometer ejuipped with the damaged rotor was repeated after three days, wilh identical results.

On the other hand, atthough the case of Anemometer 2 is different, with a damaged cup in alignment with the other two, it can be observed that the damaeced cup has a slight tilt anele when compared to the other cups in the rotor. It should be pointed oul that titted cups have been recently introduced in some cup anemometers such as Thies Ctima 4.3351 1301. In adelition, in other patents regarding anemometer tilted cups [31]. these rotors are claimed to have a higher rotation speed when compared with non-litied cups rotors.

Reverting to the anomaly detection problem, it should be pointed out that if is very difficult to find out if a cup 

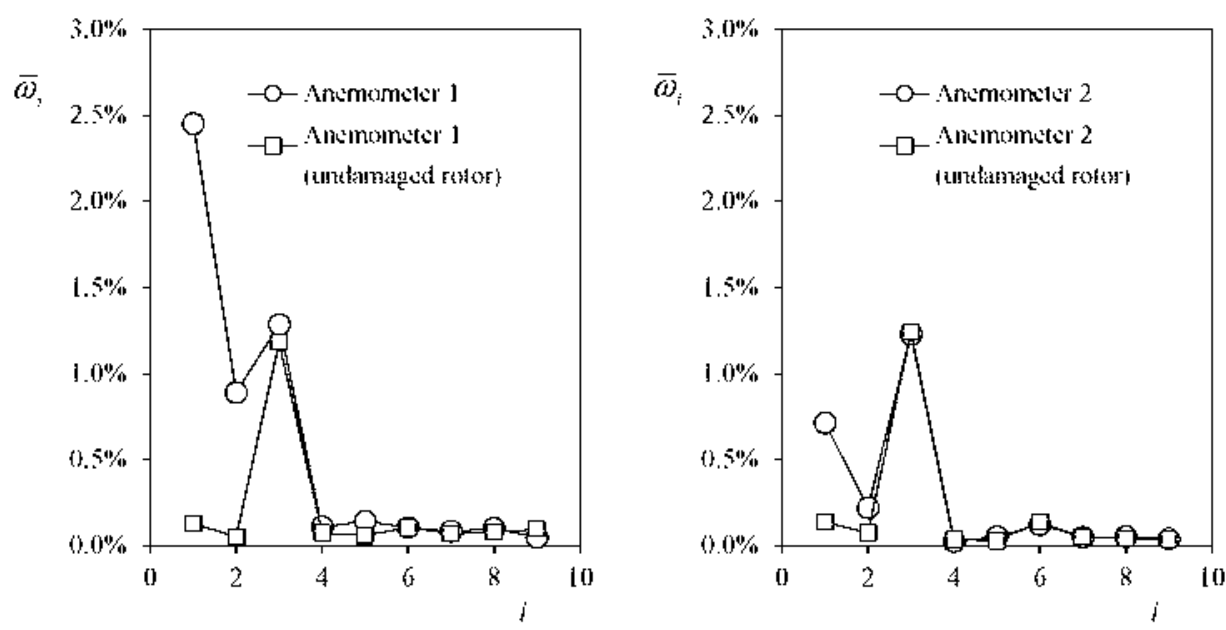

Figure 7. Non-dimensional areraged harmonic kerns calculated fom the bourier series decomposition of the rolational speed of

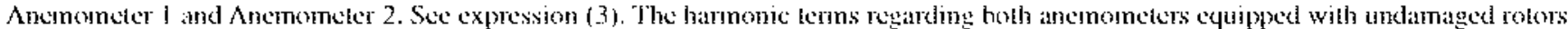
have been inclukied in the graphis.

anemometer is damaged based only on the lincarity of the calibration results. As previously stated both anemometers studied were clearly damaged. showed linear transfer lunctions and somehow a better aerodynamic behavior than the one measured with an undamaged rotor. Nevertheless. even showing a good perlormance during the calibration process, Anemometer 1 was clearly alfected by the rotor damage. which, havine changed its size, also modifics the acrodynamics. As a result, a stable equilibrium state (that is, the rotor does not move and remains at a fixed position) is produced al low wind speed, which is translated into quite a high starting threshotd speed. In figure 5, the measured wind specel of Anemometer 1, $V_{A}$, is ploted as a lunction of the wind specd. $V$, in wo different siluations, for increasing wind specds from $V=1,158$ of $V=7.949 \mathrm{~m} \mathrm{~s}^{-1}$ and for decreasing wind specds starting from $V=7.949$ lo $V=1.158 \mathrm{~m} \mathrm{~s}^{-1}$. It can be observed in the figure that the slarting threshotel speed is around $V=5.890 \mathrm{~m} \mathrm{~s}^{-1}$, whereas the starting speed specilied by the manufacturer is $V=0.2 \mathrm{~m} \mathrm{~s}^{-1}$. Furthermore, it should be noted that even in this equilibrium slate at low wind speeds. Anemometer 1 can give latse measurements produced by the oscillations of the rotor produced as a result of its interaction with the turbulent wake created downstream from the anemometer"s "neck" (Vector Instruments A 100 J.K anemometers are equipped with a 25 pulse per tun opto-electronic output signat system 119], therefore, a slight rotor oscitlation can produce a train of pulses). In figure 6 , the voltage oulpul of the anemoncter during $20 \mathrm{~s}$ is ploted for $V=3.524 .3 .997$, $4.470,4.944,5.417$ and $5.890 \mathrm{~m} \mathrm{~s}^{-1}$ wind speed, while the rotor was oscillatine at the cquilibrium position. In the figure, it can be appreciated that as the wind speed increases, the oscillations of the rotor produce a higher number of pulses. Therelore, a lalse measurement of the wind speed is recorded by the system. Iinally, the transition from the oscillating cquilibrium state to the rotation state of Anemometer 1 at $V=5.890 \mathrm{~ms}^{-1}$ (i.c. when the anemoneter rotor starts to rolate, generating a much higher putse frequency), can be observed in the bottom graph of figure 6 .
One solution in order to detect anemometer anomalies propcrly comes from the Iourier analysis of the output sienat, not directly, but by stuklying the hamonic terms in cach rotation as indicated in section 2 . In fieure 7 , the results of the aforementioned hannonic analysis are shown. Both anemonecrs. Anemometer 1 and Anemoneter 2, present a high value of the first harmonic kenn, $\overline{a \mu}$, in comparison with the figures presented by both ancmometers when equippod with undamaged rotors. This first hamonic term theoretically reliects perturbations on the ancmometer rotor's rotation that are repeated in every turn [18]. Therefore, any non-axisymmetric detait of the rotor geometry might proxluce an acrolynamic perturbation in each turn. The results agree with this statement; the dimage on the row being perfectly reliected in the graphs of figure 7 when compared to the results related to the undamased rotors.

\section{Conclusions}

The perlonnance of two damaged-on-the-fied Class-1 cup anemometers (Vector Instruments A $100 \mathrm{~L}, \mathrm{~K}$ ) has been studied. The most significant conclusions resulting from this work are:

- Damaged rotors can produce a more efficient acrolynamic behavior when compared to undamaged rotors.

- Damaged-rotor anemometers can show a perfectly linear transfer function. However, they might also change the anemometer starting threshold speed.

- Ihe proposed fourier analysis is capable of detecting the acrodynamic anomalies/perturbations produced by non-axisymmetric damage on cup rotors of commercial anemometers equipped with opto-electronic ontput sienal systems.

\section{Acknowledgments}

The authors gratefully acknowledec Prof Ángel Sanz-Andrés for his encouraging support regarding the research program on cup ancmometer perlomance and I avid Carrión and Jrian 
Elder for their assistance in improving the style of the text. Prof Pindado and the co-authors are indebted to the staff of the Library at the Aeronautics and Space Engineering School (Escuela de Ingeniería Aeronáutica y del Espacio) of the Polytechnic University of Madrid (Universidad Politécnica de Madrid), for their constant support for the research carried out regarding cup anemometer performance. The authors are also grateful to STE Global Spain for their kind support.

Stefanatos N, Papadopoulos P, Binopoulos E, Kostakos A and Spyridakis G 2007 Effects of long term operation on the performance characteristics of cup anemometers European Wind Energy Conf. and Exhibition EWEC 2007 (7-10 May, Milan, Italy) pp 1-6

Papadopoulos K H, Stefanatos N C, Paulsen U S and Morfiadakis E 2001 Effects of turbulence and flow inclination on the performance of cup anemometers in the field Boundary-Layer Meteorol. 101 77-107

Kristensen L, Jensen G, Hansen A and Kirkegaard P 2001 Field Calibration of Cup Anemometers Ris $\varnothing$ National Laboratory Report Ris $\varnothing-R-1218(E N)$ (Roskilde, Denmark)

Paulsen U S, Mortensen N G, Hansen J C, Said U S and Mousa A S 2007 Field calibration of cup anemometers European Wind Energy Conf. and Exhibition (7-10 May 2007, Milan, Italy) pp 1-8

Corten G P 2001 Method for testing an anemometer Patent WO 2001035109 A1

Ema H, Funio H, Masato W, Yasuhide T, Hitoshi K, Yasuo T, Mitsuo O and Mitsuhiro I 1998 Testing apparatus and method for anemometer Patent JP 10227810 A

Frost J S, Haines D A and Klumpp R J 1982 Method and apparatus for field testing of anemometers Patent US $4365504 \mathrm{~A}$

Laguigne D and Roni-Damon B 2010 Procédé et dispositif pour vérifier le bon fonctionnement d'un anémomètre (Method and device to check the correct operation of an anemometer) Patent EP 2037284 B1

Cummings D S 2011 Apparatus and calibration method for cup anemometers having non-removable cupsets Patent US $20110283766 \mathrm{~A} 1$

Beltrán J, Llombart A and Guerrero J 2009 A bin method with data range selection for detection of nacelle anemometers faults Proc. European Wind Energy Conf. and Exhibition (EWEC) (16-19 March 2009, Marseille, France) pp 1-8

Beltrán J, Llombart A and Guerrero J 2009 Detection of nacelle anemometers faults in a wind farm Proc. Int. Conf. on Renewable Energies and Power Quality (ICREPQ 2009) (15-17 April 2009, Valencia, Spain) pp 1-6

Siebers T, Kooijman H-J and Rogers D 2008 Anemometer calibration method and wind turbine Patent US $20080307853 \mathrm{~A} 1$

Wobben A 2010 Method for monitoring a sensor Patent EP 1454058 A1

Desforges M J, Jacob P J and Cooper J E 1998 Applications of probability density estimation to the detection of abnormal conditions in engineering Proc. Inst. Mech. Eng. C $212687-703$

Cassity J, Aven C and Parker D 2012 Applying weibull distribution and discriminant function techniques to predict damaged cup anemometers in the 2011 PHM Competition Int. J. Progn. Health Manag. 3 1-7

Siegel D and Lee J 2011 An auto-associative residual processing and $\mathrm{k}$-means clustering approach for anemometer health assessment Int. J. Progn. Health Manag. $250-61$

Sun L, Chen C and Cheng Q 2012 Feature extraction and pattern identification for anemometer condition diagnosis Int. J. Progn. Health Manag. 3 8-18

Pindado S, Cubas J and Sorribes-Palmer F 2014 On the harmonic analysis of cup anemometer rotation speed: a principle to monitor performance and maintenance status of rotating meteorological sensors Measurement submitted

Pindado S, Vega E, Martínez A, Meseguer E, Franchini S and Pérez I 2011 Analysis of calibration results from cup and propeller anemometers. Influence on wind turbine annual energy production (AEP) calculations Wind Energy $14119-32$

Pindado S, Cubas J and Sanz-Andrés A 2013 Aerodynamic analysis of cup anemometers performance. The stationary harmonic response Sci. World J. 2013197325

Pindado S, Pérez J and Avila-Sanchez S 2012 On cup anemometer rotor aerodynamics Sensors (Basel) 12 6198-217

Pindado S, Pérez I and Aguado M 2013 Fourier analysis of the aerodynamic behavior of cup anemometers Meas. Sci. Technol. 24065802

Pindado S, Sanz A and Wery A 2012 Deviation of cup and propeller anemometer calibration results with air density Energies 5 683-701

Pindado S, Barrero-Gil A and Sanz A 2012 Cup anemometers' loss of performance due to ageing processes, and its effect on annual energy production (AEP) estimates Energies 5 1664-85

MEASNET 1997 Cup anemometer calibration procedure Version 1 (September 1997, updated 24/11/2008) (Madrid, Spain)

MEASNET 2009 Anemometer calibration procedure, Version 2 (October 2009) (Madrid, Spain)

ENAC 2012 Anexo Técnico. Acreditación No 134 / LC10. 095. INSTITUTO UNIVERSITARIO DE MICROGRAVEDAD 'IGNACIO DA RIVA' (available at: //www.enac.es/ documents/7020/67cfa73f-f539-4c13-8172-986daad8514a; accessed on 29 January 2014)

Sanz-Andrés A, Pindado S and Sorribes F 2014 Mathematical analysis of the effect of the rotor geometry on cup anemometer response Sci. World J. 2014537813

Dahlberg J-Å, Pedersen T F and Busche P 2006 ACCUWIND Methods for Classification of Cup Anemometers Ris $\varnothing$ National Laboratory Report Ris $\varnothing-R-1555$ (EN) (Roskilde, Denmark)

Schmoling L and Straten G 2006 Rotational anemometer Patent EP 1398637 B1

Hong S-H 2011 Asymmetric-cup anemometer Patent US $2012 / 0266692 \mathrm{~A} 1$ 